\title{
REPORT ON GAUCHER DISEASE
}

\author{
Narendran K \\ Student, Sri Venkateswara College of Engineering \\ Tamil Nadu, India
}

Navaraj Midhun N

Teacher, Velammal Vidyalaya Senior Seconday School

Tamil Nadu, India

Jai Eashwar T P

Student, Loyola College of Arts and Science

Tamil Nadu, India

Naveen Kumar S

Student, Thiyagarajar College of Arts and Science

Tamil Nadu, India

\begin{abstract}
The Main focus of the report is to bring out the basic information of the disease. Following it government data analysis is laid out which brings the details of government preparedness towards the disease. Following it a conclusion has been given
\end{abstract}

Keywords - Rare Diseases-Lysosomes-Gaucher DiseaseGovernment Data Analysis

\section{RARE DISEASES}

Rare disease is of low prevalence compared with other prevalent diseases in the general population. Rare diseases include genetic diseases, rare cancers, infectious tropical diseases and degenerative diseases where $80 \%$ of rare diseases are genetic in origin and hence impact children mostly. Each County define rare diseases differently where the common consideration in the definition are:

- Disease prevalence,

- Severity

- Existence therapeutic options.

The filed of rare diseases is complex, heterogeneous, continuously evolving and suffers from a lack of medical and scientific knowledge. About 450 rare diseases have been recorded in India says the National Policy on Treatment of Rare Diseases.

To every country rare diseases pose a significant challenge in public health systems in terms of -

- Collecting epidemiological data

- Difficulty in research and development

- Making correct, opt, secure and timely diagnosis.

\author{
Nandheeswaran M P \\ Student, Madha Medical College and Research Institute \\ Tamil Nadu, India \\ Ramya A \\ Student, PSG College of Arts and Science \\ Tamil Nadu, India
}

Logesh R

Student, PSNA College of Engineering and Technology Tamil Nadu, India

\author{
Sowbackyalakshmi J \\ Student, Madurai Medical College \\ Tamil Nadu, India
}

It brings out economic burden mainly.

World Health Organization (WHO) defines rare disease as often debilitating lifelong disease or disorder condition with a prevalence of 1 or less, per 1000 population.

Europe Union defines rare diseases as a life-threatening condition affecting no more than 5 in 10,000 people. India, like many other developing countries, currently has no standard definition of rare diseases and data on prevalence. Applying the international estimate of $6 \%$ to $8 \%$ of population being affected by rare diseases, to India, we have between 72 to 96 million people affected by rare diseases in the country.

\section{LYSOSOMES}

Lysosome was discovered by Christian de Duve (1953) named by Novikoff. These are also known as suicidal bags. Lysosomes are formed when Golgi bodies are pinched off from its tubules. These organelles are single membrane bound organelles that contain hydrolytic enzyme $0.2 \mu \mathrm{m}$ to $0.8 \mu \mathrm{m}$. Lysosomes are polymorphic cell organelles existing in four forms. Lysosomes act as waste disposal system of the cell by digesting unwanted materials and the synthesis of lysosomal enzymes is controlled by nuclear genes.

Mutations in these genes for these enzymes are responsible for more than 45 different human genetic disorders, collectively known as lysosomal storage disorders. These diseases result from an accumulation of specific substrates, due to the inability to break them down in the cell. 


\section{International Journal of Engineering Applied Sciences and Technology, 2021 \\ Vol. 5, Issue 12, ISSN No. 2455-2143, Pages 206-209 \\ Published Online April 2021 in IJEAST (http://www.ijeast.com)}

\section{GAUCHER DISEASE}

Gaucher disease results from not having enough glucocerebrosidase (GCase), an enzyme that breaks down a fatty chemical called glucocerebroside into glucose and ceramide.

Due to lack of enzyme, the body cannot break down this chemical and gaucher cells build up in areas like the spleen, liver and bone marrow.

\section{A. TYPES}

Gaucher Disease Type I, a non-neuropathic form found in western Countries where symptoms range from mild to severe and appear anytime from childhood to adulthood.

Gaucher Disease Type II, acute -non neuropathic common found in Western Countries which causes life-threatening medical problems from beginning of infancy

Gaucher Disease Type III, a Sub Acute- Neuropathic form occurring worldwide.

Another form of Gaucher disease is known as the cardiovascular type as it affects the heart, causing the heart valves to calcify. People with the cardiovascular form of Gaucher disease may also have eye abnormalities, bone disease, and mild enlargement of the spleen.

Another Form of Gaucher Disease is caused due to mutation in gene encoding SAPOSIN $\mathrm{C}$ which is an activator of Beta Glucocerebosidase

\section{B. TREATMENT TYPES}

- Enzyme replacement therapy (ERT) balances low levels of G-Case in patients through intravenous (IV) infusions

- Substrate reduction therapy (SRT) : SRT is a type oral medication that decreases the amount of glucocerebroside that the body makes, reducing excess build-up.

- Now Mostly through Recombinant DNA technology the enzyme is efficiently produced in many plants and is made available in the market

\section{INHERITANCE EFFECT}

This condition is inherited in an autosomal recessive pattern, which means both copies of the gene in each cell have mutations.

The parents of an individual with an autosomal recessive condition each carry one copy of the mutated gene, but they typically do not show signs and symptoms of the condition.

In India an Estimate says more than 5000 people are affected by Gaucher Disease

\section{CONFIRMATION TEST}

The following diagnostic tests are taken in order to confirm the Disease

\section{- BETA GLUCOSIDASE LEUKOCYTE TEST}

- Genetic Testing

- ELISA Test

- Chemical analysis of sediment from 24 hour urine collection

- Separation of glycosphinoolipids by thin layer chromatography

- Quantitative estimation of glycosphinogolipids by gas liquid chromatography

- Assessment of Beta Glucosidase enzyme to find whether the affected is homozygotes (or) Heterozygotes

- Magnetic resonance imaging for detecting bone involvement

\section{E. SIGNS AND SYMPTOMS}

- Spleen and liver enlargement: Gaucher cells build up in the spleen and/or liver, these organs become enlarged and painful.

- Low platelet count: A spleen enlarged by Gaucher disease destroys blood cells too rapidly

- Bleeding and clotting problems: With fewer platelets, patients with Gaucher disease can have bleeding issues. Low platelets can also result in particularly after dental work, surgery, trauma and delivering a baby.

- Joint pain, arthritis and joint damage: It is common for patients with Gaucher disease to experience joint pain. Gaucher disease can cause severe arthritis and joint damage, which can be permanent if the disease is untreated.

- Anemia: Gaucher cells in bone marrow reduce production of blood cells, and the spleen quickly destroys blood cells.

- Lungs: In some cases, glucocerebroside may accumulate in the lungs, causing respiratory problems.

- Bone infarction or avascular necrosis (AVN): This condition occurs when parts of the bone don't get enough oxygen, causing bone tissue to deteriorate and die.

- Hepatomology

- Splenomagaly

- Hyper-pigmentation

- Increased Bone Serum and Phospotase

- White Deposits in Corneal Epithilium

- Pulmonary Hypertension 


\section{International Journal of Engineering Applied Sciences and Technology, 2021 \\ Vol. 5, Issue 12, ISSN No. 2455-2143, Pages 206-209 \\ Published Online April 2021 in IJEAST (http://www.ijeast.com)}

\section{GOVERNMENT DATA ANALYSIS}

\section{1)Employees State Insurance Corporation-Karnataka}

Information Requested: The Requestee wants the information about list of beneficiaries who were funded by ESIC for treatment of LSD as per the Karnataka HC order

Information Furnished: No patient is taking such benefit But the statement makes doubt that the affected only could approach the court and get the order. But the statement of no one is taking benefit makes a doubt.

2)Pharmacy Council of India-Directorate General of Health Services

Information Requested: The Requestee wants details of the drugs approved in India for treatment of LSD

Information Furnished: The Drugs approved for the treatment of LSD are available on the website www.cdscoonline.gov.in

3) Department Of Pharmaceuticals - National Pharmaceutical Pricing Authority

Information Requested: The complete list of prices of drugs for Gaucher Disease

Information Furnished: The price list of the drugs for Gaucher

Disease is available on www.nppaindia.nic.in

4) Government of Tamil Nadu -Department Of Medical Education - Institute of Child Health and Hospital for Children, Egmore

Information Requested:

i. The Information about centers for treating rare genetic diseases

ii. The Present Confirmed Patients on LSD

Information Furnished:

i. The center for rare genetic disease is started as per the National Policy for Treatment of Rare Diseases at ICHM, Egmore and Madras Medical College.

ii. At present three patients have been confirmed with LSD are referred to Central Technical Committee for Enzyme Replacement Therapy

5) Government of NCT of Delhi - Maulana Azad Medical College, Delhi

Information Requested: The Requestee wants details of the National Policy for Treatment of Rare Diseases and about the status

Information Furnished: The copy of The National Policy for Treatment of Rare Diseases is been sent with the Gazette of India for uphold of the policy.

6) Ministry Of Health and Family Welfare

Information Requested:

The Requestee wants the following details

i. About the Implementation of National Policy for treatment

of Rare Diseases

ii. PSU's manufacturing the drugs for the rare diseases

iii. The Number of People affected by Gaucher Disease in India

iv. Basis for pricing the drugs of LSD and its affordability Information Furnished: i. The Committee constituted to review the policy is in the process of finalizing the draft

ii, iii, iv No Information is available

7) Hints From the National Policy

The High Court of Delhi in W.P. (C) No. 4444/2016, W.P. (C) No. 7730/2016, and W.P. (C) No. 7729/2013, directed Ministry of Health \& Family Welfare to frame a "national policy on treatment of rare diseases'.

The Government of India had appointed high level committees to make recommendations towards formulation of 'Policy on treatment of Rare Diseases'. The committees made several recommendations, which have been discussed below. The Policy highlights the measures and steps, both in the short as well as in the long term, that need to be taken to deal comprehensively with rare diseases and that had been elaborately dealt here also.

Similarly, the Government of National Capital Territory of Delhi had also appointed a high powered interdisciplinary committee on rare diseases. The various committees that were appointed and their recommendations were discussed below one by one as follows:

a. Professor V.K. Paul Committee- Report on Prioritization of Therapy for Rare Genetic Disorders

The committee in their Report 'prioritisaiton of therapy for rare genetic disorders' attempts to elaborate the available therapies and prioritize genetic disorders based on resources, cost of therapy (one time vs. long term), outcome (evidencebased), quality of life and published guidelines.

The Committee had categorized genetic disorders into three categories and made recommendations for each category As about $80 \%$ of rare diseases are genetic in nature, the Committee also recommended that it is important to provide genetic counseling and offer prenatal testing to the families with genetic disorders, as it will provide them an option about giving birth to children with rare diseases.

b. Professor I C Verma Committee- Report on 'Guidelines for Therapy and Management'

The Sub-committee reviewed the burden and definitions of rare diseases globally as well as in India, availability of drugs and treatment options for various rare diseases, cost estimation and evidence on treatment outcomes.

The committee also considered the challenges in treatment of rare diseases, reviewed the funding mechanisms for treatment of rare diseases in several countries and made recommendations for mechanisms of approving and regulating access and other inputs for formulating a national plan on rare diseases. The Sub-committee specifically evaluated the availability and efficacy of treatment and cost of rare disorders of immediate relevance in India, namely - Lysosomal Storage Disorders (LSDs), which is treatable with Enzyme Replacement Therapies (ERTs). The sub-committee calculated the annual cost of the available therapies for a $10 \mathrm{~kg}$ child.

The Sub-committee notes that various countries have used different approaches for funding treatment for rare diseases. As treatment is out of reach of most families, many countries 
cover the cost through their National Health Services, for instance, most of the European countries. In USA once a therapy is approved by the FDA, the insurance companies cover the cost. In many emerging economies, the government funds the treatment of rare diseases, for instance in Egypt, Thailand, Argentina, Chile, Peru, Serbia, Malaysia and Philippines. The committee, concludes that there is a need for the government to play a role in evolving a funding mechanism for treatment of rare diseases and made recommendations for formulation of a national policy for treatment of rare diseases.

\section{c. The D.K. Tempe Committee Report}

The Committee considered the prohibitive costs of treatment and competing priorities of public health and resource allocation; inadequate prevalence data; and still unravelling diagnostic and treatment landscape.

It suggested that the national policy should cover treatment in a phased manner, starting with rare genetic disorders, for which treatment with good clinical outcome is available. The policy could be progressively revised with increased knowledge and clarity about epidemiological data, diagnostic and treatment options, evidence on clinical outcomes, reduced cost of drugs, etc...

Expanding on the challenge of economic evaluation and resource allocation for rare diseases, the committee gave the example of cost of ERTs to treat LSDs and stated that Enzyme Replacement Therapy (ERTs) is very costly and lifelong and the public health system cannot support it in a cost-effective way with its own funds.

The annual recurring cost of one patient with ERT could range from $1.8-17.0$ lacks per $\mathrm{kg}$ of body weight. This means that for a child weighing $10 \mathrm{kgs}$, the cost would be between 18 lacks to 1 crore 70 lacks.

\section{REFERENCE}

[1] K.NARENDRAN - EMPloyees' State InSURANCE CORPORATION-KARNATAKA RTI APPLICATION NUMBER : ESCIO/R/2018/52021-RESPONSE LETTER

[2] K.NARENDRAN - DiReCtorate GENERAL OF HEALTH SERVICES RTI APPLICATION NUMBER : PHRCI/R/2018/50231-RESPONSE LETTER

[3] K.NARENDRAN - HEALTH AND FAMILY Welfare DEPARTMENT(H1) GOVT LETTER NUMBER 42068/H1/2018-1/2-RESPONSE LETTER

[4] K.NARENDRAN - Government OF NCT OF DelhiMaulana Azad Medical Collage(Co-Ordination) F.NO : 150(2066)/RTI/MAMC/2018-19/134

[5] K.NARENDRAN - Ministry OF Health And FAMily Welfare-Government Of India- National Policy For TREATMENT OF RARE DisEASES-RESPONSE LETTER 